\title{
SISTEMAS DE CLASSIFICAÇÃO DE PACIENTES (SCP): ELABORAÇÃO DE UM INSTRUMENTO DE SCP PARA UMA UNIDADE DE TERAPIA INTENSIVA
}

\author{
Fernanda Silva Ruiz José1 \\ Giovanna Alves Nicomedes Martins ${ }^{2}$ \\ Adriele de Martins Ribeiro ${ }^{3}$ \\ Jocimara Aparecida Pontes Ferreira ${ }^{4}$ \\ Maria Aparecida Xavier Moreira da Silva ${ }^{5}$
}

RESUMO: Um sistema de classificação de pacientes (SCP) ideal, sob o ponto de vista da enfermagem, é aquele que utiliza instrumentos que permitam resultados seguros para a avaliação dos pacientes e da unidade, objetivando um dimensionamento adequado para garantir a qualidade da assistência à saúde e segurança do paciente. Este estudo teve como objetivo principal elaborar um instrumento de SCP para atendimento de pacientes críticos em uma UTI Adulto. Trata-se de um estudo do tipo pesquisa-ação, descritiva, prospectiva e com abordagem quanti-qualitativa, que foi realizada em uma Instituição de Saúde localizada no Município de Jacareí, na região do Vale do Paraíba, Estado de São Paulo. Os resultados apontaram que o perfil epidemiológico de atendimento, no momento da coleta de dados, teve a predominância de atendimento de pacientes com Covid-ıg e suas complicações $(23,7 \%)$, seguido das doenças cerebrovasculares (15,8\%). Dentre os SCP (TISS-28, NAS e Fugulin) avaliados pelo teste de normalidade de Shapiro Wilk, o Fugulin se apresentou ser o SCP mais sensível a ser aplicado na UTI Adulto para atendimento desse perfil de pacientes.

Palavras-chave: Unidade de Terapia Intensiva. Carga de Trabalho. Recursos humanos de Enfermagem.

\footnotetext{
I Graduanda em Enfermagem pela Universidade de Mogi das Cruzes, SP.

${ }^{2}$ Graduanda em Enfermagem pela Universidade de Mogi das Cruzes, SP.

${ }^{3}$ Graduanda em Enfermagem pela Universidade de Mogi das Cruzes, SP.

4 Mestre em Semiótica, Tecnologia da Informação e Educação pela Universidade Braz Cubas, Especialista em Controle de Infecção Relacionada à Assistência à Saúde (IRAS) pela Universidade Federal de São Paulo UNIFESP e em Administração Hospitalar pela Universidade de Ribeirão Preto - UNAERP. Docente do Curso de Graduação em Enfermagem da Universidade de Mogi das Cruzes - UMC, ministrando as disciplinas de Cliente de Risco, Moléstias Infecciosas e Enfermagem em Pronto Socorro. Experiência na área assistencial em Unidade de Terapia Intensiva Cardiológica e Oncológica. Consultora da Empresa Actually Assessoria em Educação Continuada.

5 Mestre em Políticas Públicas pela Universidade de Mogi das Cruzes - UMC, Especialista em Administração Hospitalar pela Universidade de Ribeirão Preto - UNAERP, Graduada pela Universidade de Mogi das Cruzes - UMC. Atualmente, Docente do Curso de Graduação em Enfermagem, ministrando as disciplinas de Semiologia em Enfermagem, Semiotécnica em Enfermagem, Enfermagem em Home Care e Tópicos Avançados II. Orientação de Projetos de pesquisa e iniciação científica nas áreas de concentração em saúde, gestão e gerenciamento, suporte para o cuidado e políticas públicas de saúde, e docente do Curso de PósGraduação de Gestão em Saúde da Universidade de Mogi das Cruzes. Experiência como enfermeira assistencial na área de clínica médica e cirúrgica, centro cirúrgico e oncologia, e na área de gestão e Educação Continuada. Diretora Técnica e consultora da Empresa Actually Assessoria em Educação Continuada.
} 
ABSTRACT: An ideal patient classification system (PCS), from the point of view of nursing, is one that uses instruments that allow safe results for the assessment of patients and the unit, aiming at an adequate dimension to ensure the quality of health care and patient safety. The main objective of this study was to develop a SCP instrument for the care of critically ill patients in an Adult ICU. This is an action-research study, descriptive, prospective and with a quanti-qualitative approach, which was carried out in a Health Institution located in the municipality of Jacareí, in the region of Vale do Paraíba, State of São Paulo. The results showed that the epidemiological profile of care, at the time of data collection, had a predominance of care for patients with Covid-ig and its complications (23.7\%), followed by cerebrovascular diseases (15.8\%). Among the PCS (TISS-28, NAS and Fugulin) evaluated by the Shapiro Wilk normality test, Fugulin proved to be the most sensitive PCS to be applied in the Adult ICU to meet this profile of patients.

Keywords: Intensive Care Unit. Work Load. Nursing Human Resources.

\section{INTRODUÇÃO}

O processo de cuidar e o processo de gerenciar podem ser considerados como as principais dimensões do trabalho do enfermeiro em seu dia a dia. O planejamento do cuidar caracteriza-se pela aplicabilidade do Processo de Enfermagem, conforme descrito na Resolução COFFEN 358/2009, por meio da observação, o levantamento de dados, diagnóstico de enfermagem, planejamento, implementação e na avaliação, fortalecendo-se ainda pelo processo de interação entre pacientes e trabalhadores da enfermagem e entre diversos profissionais de saúde. Já o processo de administrar tem como foco organizar a assistência e proporcionar a qualificação do pessoal de enfermagem, através da educação continuada, apropriando-se, para isso, dos modelos e métodos de administração, da força de trabalho da enfermagem e dos equipamentos e materiais permanentes (CAMELO et al., 2012; COFEN, 2009).

Segundo Fugulin et al. (2012), por meio da Resolução 293/2004, atualmente revogada pela Resolução COFEN 543/2017, o COFEN determinou medidas de dimensionamento de pessoal relacionado aos profissionais de enfermagem em relação à cuidados prestados em instituições de saúde. Descreve que para a realização de assistência de enfermagem no período das 24 horas, cada unidade de internação deverá realizar o seu dimensionamento de enfermagem levando em consideração o uso de um "SCP, as horas de assistência de enfermagem, a distribuição do percentual do total de profissionais de enfermagem e a proporção de profissional/paciente”. 


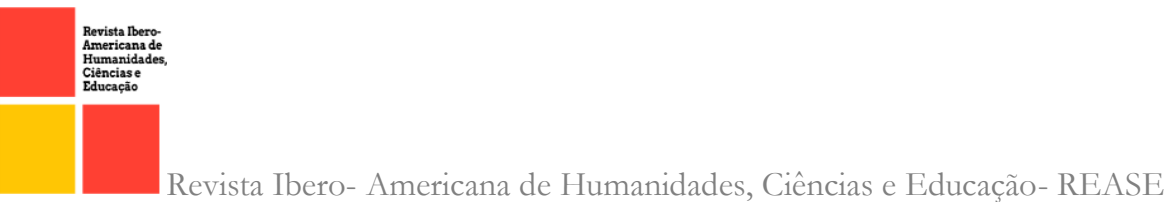

De acordo com a Resolução COFEN 543/2017, os parâmetros relacionados à carga horária se apresentam estabelecidos da seguinte forma: paciente com cuidados mínimos - 4 horas; pacientes em cuidados intermediários - 6 horas; pacientes com cuidado de alta dependência - Io horas; pacientes com cuidados semi-intensivos - Io horas e, para pacientes com cuidados intensivos - I8 horas (COFEN, 2017).

Ainda no contexto do dimensionamento de pessoal, a referida resolução também sugere, de acordo com o "Anexo I" que descreve sobre os conceitos e metodologia dos cálculos de pessoal de enfermagem, os instrumentos de classificação de Pacientes (SCP): Dini (2014); Fugulin, Gaidzinski e Kurcgant (2005), Martins (2007), Perroca e Gaidzinski (1998) e Perroca (20II) como instrumentos metodológicos para subsidiar o cálculo do dimensionamento (COFEN, 2017).

Porém, nenhum destes apresentados pela Resolução COFEN 543/2017 são sugeridos especificamente para atender as necessidades de cuidados do perfil de pacientes atendidos em Unidades de Terapia Intensiva. A partir do exposto, este estudo traz como hipótese que o instrumento de Sistema de Classificação de Pacientes TISS-28 (Therapeutic Intervention Scoring System) se apresentará como o instrumento mais sensível para atender as necessidades de cuidados dos pacientes internados na Unidade de Terapia Intensiva da Instituição de Saúde, onde será o cenário deste estudo, e para testar esta hipótese, este estudo será guiado pelas questões norteadoras: "Qual é o perfil epidemiológico de atendimento da UTI Adulto?” e "Qual o instrumento de SCP de melhor sensibilidade para classificação dos pacientes na UTI Adulto?”.

Esse estudo se apresenta com imensa relevância, pois, o uso de um adequado instrumento de SCP, em uma Unidade de Terapia Intensiva, permitirá a realização do dimensionamento de pessoal de enfermagem ideal para que a assistência de enfermagem seja realizada de forma individualizada, humanizada, com qualidade e segura, de acordo com os princípios da segurança do paciente frente à assistência à saúde.

O objetivo geral desse estudo foi elaborar um instrumento de SCP para atendimento de pacientes críticos em uma UTI Adulto. E o objetivo específico deste estudo foi identificar o perfil epidemiológico dos pacientes atendidos na UTI; identificar, por meio de revisão integrativa da literatura, os instrumentos de SCP utilizados para classificação de pacientes 
em UTI, com o perfil epidemiológico deste estudo; testar e avaliar na UTI, cenário deste estudo, a sensibilidade dos principais SCP utilizados para classificação de pacientes críticos.

\section{MÉTODO}

Trata-se de um estudo do tipo pesquisa-ação, descritiva, prospectiva e com abordagem quanti-qualitativa, guiada por um estudo de revisão integrativa da literatura, que foi realizado em uma Instituição de Saúde localizada no Município de Jacareí, na região do Vale do Paraíba, Estado de São Paulo.

Esse estudo teve como cenário de pesquisa uma Unidade de Terapia Intensiva de atendimento à adultos (UTI Adulto) da Instituição de Saúde denominada Hospital São Francisco de Assis que se classifica, de acordo com o seu Estatuto Social, como "pessoa jurídica de direito privado, sem fins econômicos, de caráter beneficente, filantrópico e assistencial”. A UTI Adulto foi inaugurada no ano de $2001 \mathrm{e}$, até o momento da coleta de dados, contava com io leitos para atendimento (HSFA, 202I).

A população e amostra foi composta por 4 enfermeiros e 50 prontuários de pacientes internados na Unidade de Terapia Intensiva da referida IS, cenário deste estudo. Como material foram utilizados 02 (dois) questionários, o "Questionário - Enfermeiros" composto por 12 questões mistas (abertas e de múltipla escolha), sendo que o6 referem-se aos dados sociodemográficos, e as outras o6 questões representam os dados específicos dessa pesquisa (conhecimento sobre os Sistemas de Classificação de Pacientes - SCP) e, o "Questionário - Familiar/Paciente" é composto por três partes: a primeira, caso o paciente não tenha condição de responder, é designada ao familiar responsável pelo paciente, composto por questões sociodemográficas.

Além desses instrumentos, foram utilizados 3 (três) formulários destinados à coleta de dados junto aos prontuários dos pacientes internados na UTI, que são os instrumentos dos Sistemas de Classificação de Paciente (SCP) no modelo Fugulin, NAS e TISS-28, elaborados pelos autores com fundamentação teórica respectivamente em Santos et al. (2007); Queijo (2002) e Padilha et al. (2005).

Foram critérios de inclusão: enfermeiros que atuam de forma direta ou indiretamente (enfermeiros assistenciais / administrativos, supervisores de enfermagem, coordenadores de enfermagem, gerente de enfermagem) na assistência aos pacientes internados na UTI, 


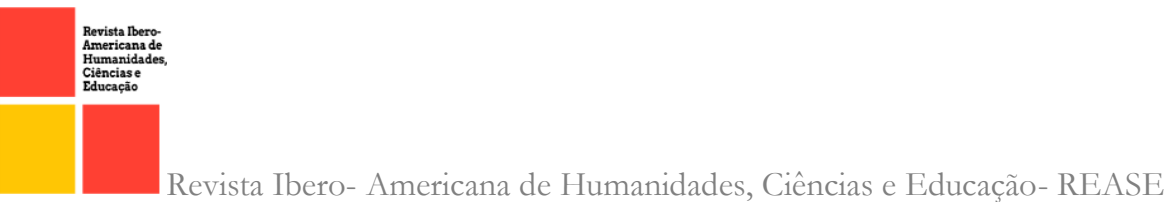

cenário desta pesquisa; enfermeiros que atuam na UTI por tempo superior a 6 meses; enfermeiros que aceitaram a participar desta pesquisa, por meio de sua assinatura no TCLE; prontuários de pacientes internados na UTI, por um tempo de internação superior a 24 horas; prontuários de pacientes em que o familiar, responsável e, ou o próprio paciente autorizar a coleta de dados, por meio de sua assinatura no TCLE. Foram critérios de exclusão: Enfermeiros que apontassem ou demonstrassem o desconhecimento sobre o SCP; participação de enfermeiros que não tiveram informação sobre o processo de coletas de dados em razão de folgas e férias na escala de trabalho no período em que a coleta de dados foi realizada.

No contexto da revisão integrativa foram utilizados como critérios de inclusão: artigos publicados nos últimos 20 anos, nas bases de dados da LILACS (Literatura LatinoAmericana e do Caribe em Ciências da Saúde) e BDENF (Banco de Dados em Enfermagem), com texto completo e de acesso gratuito, no idioma português e, os critérios de exclusão foram artigos duplicados nas bases de dados e os que não atenderam à temática desse estudo.

Para atendimento dos princípios éticos e legais, o projeto de pesquisa foi apresentado à uma Instituição de Saúde inserida em um município de Jacareí, que pertence à região do Vale do Paraíba, para apreciação e aprovação, após autorização para a realização da pesquisa, o projeto foi submetido ao Comitê de Ética em Pesquisa (CEP) da Universidade de Mogi das Cruzes para apreciação e aprovação, conforme determina a Resolução CNS 466, de dezembro de 2012.

Após aprovação do CEP, de acordo com o Parecer Consubstanciado de no 3.530.352, os enfermeiros e os familiares/responsáveis pelos pacientes internados na UTI foram informados sobre os objetivos da pesquisa e os seus direitos conforme se determina na Resolução CNS 466/2o12 e, os dados foram coletados.

Para a coleta nas bases de dados foram utilizados os seguintes descritores, testados no DeCS (descritores em Ciências da Saúde) em cruzamento: enfermagem, unidade de terapia intensiva, unidade de terapia intensiva de adulto, recursos humanos de enfermagem, assistência de enfermagem, segurança do paciente, carga de trabalho, cuidados intensivos, índice de gravidade, administração de pessoal, avaliação em enfermagem, processos de enfermagem, processos de enfermagem, avaliação em saúde, 
classificação e Nursing Activities Score. Além desses descritores foram pesquisadas as Resoluções pertinentes para a construção do Referencial Teórico.

Os dados procedentes dos questionários foram tratados, codificados, categorizados e analisados por meio da Análise de Conteúdo a partir da técnica da Análise Temática e na forma de frequências relativas e absolutas para variáveis categóricas. A Análise de Conteúdo, segundo Minayo (2000, p. 203) relaciona estruturas semânticas com estruturas sociológicas, articula a descrição e análise dos textos com os fatores que determinam suas características, "fazer uma análise temática consiste em descobrir os núcleos de sentido que compõem uma comunicação cuja presença ou frequência signifiquem alguma coisa para o objetivo analítico visado".

A avaliação da normalidade das variáveis, para a análise dos instrumentos de SCP, foi realizada por meio do teste de normalidade de Shapiro Wilk. Segundo Miot (2017) existem diversos tipos de testes estatísticos que analisam a regulagem dos dados obtidos à distribuição normal, a partir de pressupostos e algoritmos distintos, que resultam em parâmetros de normalidade. O teste de Shapiro-Wilk, proposto em 1965, testa a hipótese nula que uma amostra obtida de uma população, tem distribuição normal frente aos dos dados obtidos.

\section{RESULTADOS}

Neste capítulo estão descritos os resultados da coleta de dados realizada com os enfermeiros e informações coletadas nos prontuários dos pacientes, bem como a apresentação dos resultados obtidos no estudo de revisão integrativa da literatura, utilizado para a construção do referencial teórico.

\section{RESULTADOS DOS QUESTIONÁRIOS APLICADOS AOS ENFERMEIROS}

A primeira etapa da coleta de dados foi realizada no período de março a setembro do ano de 2020, onde se obteve o preenchimento dos questionários pelos enfermeiros e a coleta dos dados provenientes dos prontuários, onde as informações obtidas foram cruciais para a construção de um SCP (Sistema de Classificação de Pacientes), mais sensível no âmbito de uma Unidade de Internação Adulto. No entanto, mediante aos Protocolos para atendimento de pacientes com COVID-ı́ implantados na Instituição de Saúde, os questionários 


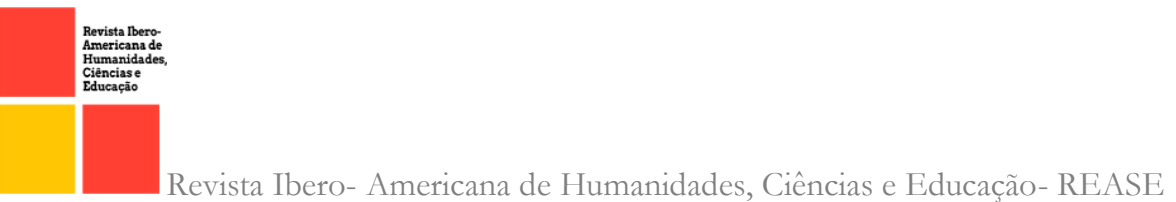

direcionados aos familiares/pacientes não foram aplicados, os familiares foram orientados quanto aos objetivos da pesquisa, riscos e benefícios e demais aspectos éticos e legais e após lhes foram entregues o TCLE.

De acordo com os dados sociodemográficos, os resultados apontam que a metade (50\%) dos profissionais são do sexo feminino, estão na faixa etária entre 4I à 59 anos (50\%). Quanto à formação profissional, a maioria apresenta tempo de formação entre 12 a 17 anos, com tempo de atuação entre 6 a II anos e as pós-graduações mais citadas pelos enfermeiros foram em UTI (28,6\%); Urgência/Emergência; Pacientes Críticos Cardiológicos; Enfermagem do Trabalho e Nefrologia com I4,3\%, respectivamente.

Frente ao conhecimento sobre o uso de um SCP para o dimensionamento de pessoal na UTI Adulto, entre os sistemas de classificação citados pelos enfermeiros, evidenciou-se o uso do Fugulin (6o\%), seguido do NAS (Nursing Activities Score) e ECA (Escala de Complexidade Assistencial) com 20\%, respectivamente. Conforme apresentado pelo Enf 4, os instrumentos utilizados na Unidade de Terapia Intensiva são o NAS e o Fugulin, e de acordo com o Enf2, o NAS é o instrumento que visa medir o tempo de assistência de enfermagem em uma Unidade de Terapia Intensiva. Quando questionados se conhecem outros instrumentos de SCP, foi possível analisar que ıо\% dos participantes possuem conhecimento sobre essas metodologias já citadas para classificação de pacientes, mas, não houve menção do uso do SCP TISS-28.

Foi perguntado aos enfermeiros qual o perfil de complexidade assistencial dos pacientes, segundo o Sistema de Classificação de Pacientes utilizado na UTI e, a maioria (50\%) mencionou que os pacientes são de média complexidade assistencial. Quando questionados se já testaram outros instrumentos de SCP, 75\% dos enfermeiros disseram que não. No entanto, a Enf3 mencionou que a Escala de Braden fornece parâmetros para avaliação dessa complexidade, no entanto, a escala de Braden não se caracteriza como instrumento de sistema de classificação de pacientes e sim, em uma escala preditiva para avaliação de risco de lesão por pressão.

E como último tópico questionado, foi solicitado aos enfermeiros como se caracteriza o dimensionamento de pessoal de sua unidade de trabalho e, 66,7\% ressaltou que é através da Escala de Fugulin e 33,3\% pelo ECA. Para o Enf 2, o dimensionamento se caracteriza com base em uma escala semanal de leitos sempre realizando rodízios e mais o nível de 
complexidade do paciente. Vale ressaltar que a ECA, de acordo com Brito (2012) é a denominação do grau de complexidade assistencial dado ao instrumento de classificação assistencial Fugulin, entende-se então, que todos os participantes elegeram o SCP Fugulin para o dimensionamento de pessoal da UTI, cenário desse estudo.

\section{RESULTADOS DO PREENCHIMENTO DOS INSTRUMENTOS DE SCP (NAS, FUGULIN E TISS-28) COM DADOS DOS PRONTUÁRIOS DOS PACIENTES ( $\mathrm{N}=$ 50) INTERNADOS NA UTI}

Tabela I - Média geral do tempo de internação e dos escores de cada paciente de acordo com os SCP: NAS, Fugulin e TISS-28. Jacareí, 2021.

\begin{tabular}{|c|c|c|c|c|}
\hline \multirow[t]{2}{*}{ Paciente } & \multirow[t]{2}{*}{$\begin{array}{c}\text { Ternpo de } \\
\text { intemaçăo (dias) }\end{array}$} & \multicolumn{3}{|c|}{ Média dos SCP de cada paciente } \\
\hline & & NAS & Fugulin & TISS- 28 \\
\hline 1 & 9 & 89,5 & 29,4 & 16,0 \\
\hline 2 & 18 & $49: 5$ & $25: 9$ & 15.7 \\
\hline 3 & 12 & 74,3 & 42,7 & 33,5 \\
\hline 4 & 8 & 64,3 & 29,4 & 21,1 \\
\hline 5 & 12 & 76,0 & 26,3 & 20,4 \\
\hline 6 & 3 & 45,1 & 28,3 & 15,7 \\
\hline 7 & 2 & 48.1 & 23.0 & 14.5 \\
\hline 8 & 4 & 64,9 & 28,0 & 13,3 \\
\hline 9 & 3 & 46,0 & $1 \%, 3$ & 10,0 \\
\hline 10 & 3 & 53.0 & 20.0 & 11.7 \\
\hline 11 & 2 & 61,6 & 26,0 & 21,5 \\
\hline 12 & 2 & 55,2 & 19,0 & 16,0 \\
\hline 13 & 7 & 95,1 & não informa do & $3: 2,0$ \\
\hline 14 & 9 & $49 ; 0$ & 15,8 & 24,0 \\
\hline 15 & 7 & $69: 4$ & 30,1 & 26,7 \\
\hline 16 & 8 & 66,8 & 31,5 & 13,6 \\
\hline 17 & 21 & 01,8 & 37,2 & 29,0 \\
\hline 18 & 28 & 68.6 & 42.0 & 37.0 \\
\hline 19 & 20 & 76,2 & 39,6 & 399,0 \\
\hline 20 & 18 & $90: 4$ & 46,0 & 33,0 \\
\hline 21 & 8 & 64.6 & 20.5 & 1010 \\
\hline 22 & 24 & 80,5 & 48,1 & 28,4 \\
\hline 23 & 12 & 67,0 & 18,8 & 13,2 \\
\hline 24 & 0 & 64,6 & 30,2 & 17,2 \\
\hline 25 & 6 & 63,9 & 19,3 & 20,3 \\
\hline 26 & 10 & 63.3 & 33.1 & 15.0 \\
\hline 27 & 3 & 44,7 & 14,7 & 10,0 \\
\hline 28 & 7 & 03,7 & 29,9 & 17,5 \\
\hline 29 & 4 & 51.7 & 22.0 & 13.0 \\
\hline 30 & 2 & 61,4 & 26,5 & 16,0 \\
\hline 31 & 2 & 61,4 & 26,5 & 18,5 \\
\hline 32. & 7 & 58.9 & 28.7 & 14.7 \\
\hline 33 & 3 & 63,9 & 33,4 & 13,6 \\
\hline 34 & 14 & 64,3 & 31,0 & 15,9 \\
\hline 35 & 8 & 41,9 & 24,5 & 12,3 \\
\hline 30 & 7 & $60 ; 0$ & 31,1 & 15,0 \\
\hline 37 & 26 & 69.0 & 44.0 & 30.5 \\
\hline 38 & 7 & 62,9 & 24,7 & 12,4 \\
\hline 39 & 3 & 64,8 & 29,0 & $1 \%, 6$ \\
\hline 40 & 2 & 47.3 & 20.0 & 14.0 \\
\hline 41 & 24 & 84,5 & 45,6 & 39,2 \\
\hline 42 & 20 & 85,5 & $37 ; 9$ & 25,9 \\
\hline 43 & 25 & 86,6 & 44 & 37,5 \\
\hline 44 & 20 & 85,5 & $37 \geqslant 9$ & 24,7 \\
\hline 45 & 5 & 55.6 & 31 & 18.2 \\
\hline 16 & 8 & 390,9 & 26,8 & 13,3 \\
\hline 47 & 4 & 33,5 & 28,2 & 11,2 \\
\hline 48 & 9 & 56.8 & 33.3 & 24.3 \\
\hline 49 & 5 & 38,6 & 18,2 & 11,2 \\
\hline 50 & 9 & 37 & 22,3 & 7 \\
\hline Média Geral & 0,8 & 62,6 & 20 & 21,4 \\
\hline
\end{tabular}

Fonte: Elaborado pelos pesquisadores com base nos dados coletados.

Os primeiros dados foram coletados de 42 prontuários de pacientes internados na UTI, no período de março a setembro de 2020. Na segunda etapa, a coleta de dados foi 
realizada no período de abril à maio de 202I, onde foram coletados o restante dos dados dos pacientes pendentes ( 8 prontuários) para completar a amostra proposta $(n=50)$.

Foi realizado o preenchimento dos instrumentos de SCP (NAS, FUGULIN e TISS28), para cada paciente (prontuário avaliado), quanto ao grau de dependência dos cuidados de enfermagem (Fugulin) ou de acordo com os índices de tempo de trabalho da enfermagem (NAS e TISS-28). Os dados foram transcritos em uma planilha do Excel ${ }^{\circledR}$ e tabulados, utilizando-se a média dos escores obtidos de cada paciente por tempo de internação e de acordo com os SCP propostos (Tabelar).

Conforme demonstrado na Tabela I, o tempo médio de internação dos 50 pacientes foi de 9,8 dias, a média dos escores obtidos de acordo com os SCP são: com o instrumento do NAS a média foi de 62,6 pontos, para o FUGULIN obteve-se 29 pontos e com o instrumento do TISS- 28 o resultado obtido foi $2 \mathrm{I}, 4$ pontos.

\section{RESULTADOS DOS TESTES DE NORMALIDADE DE SHAPIRO WILK}

O teste de normalidade de Shapiro Wilk teve a finalidade de identificar o padrão de normalidade na aplicabilidade destes instrumentos, o resultado mostrou que o instrumento mais sensível foi o SCP Fugulin ao invés do TISS-28, o qual tínhamos como hipótese de maior sensibilidade para a unidade em questão. Para a utilização do teste de normalidade de Shapiro Wilk considerou-se o nível de significância de 5\%.

\section{SHAPIRO WILK PARA O SISTEMA DE CLASSIFICAÇÃO NAS}

Figura I - Aplicabilidade do teste de Shapiro para os dados apresentados no Sistema de Classificação de Pacientes - NAS. Jacareí, 2021.

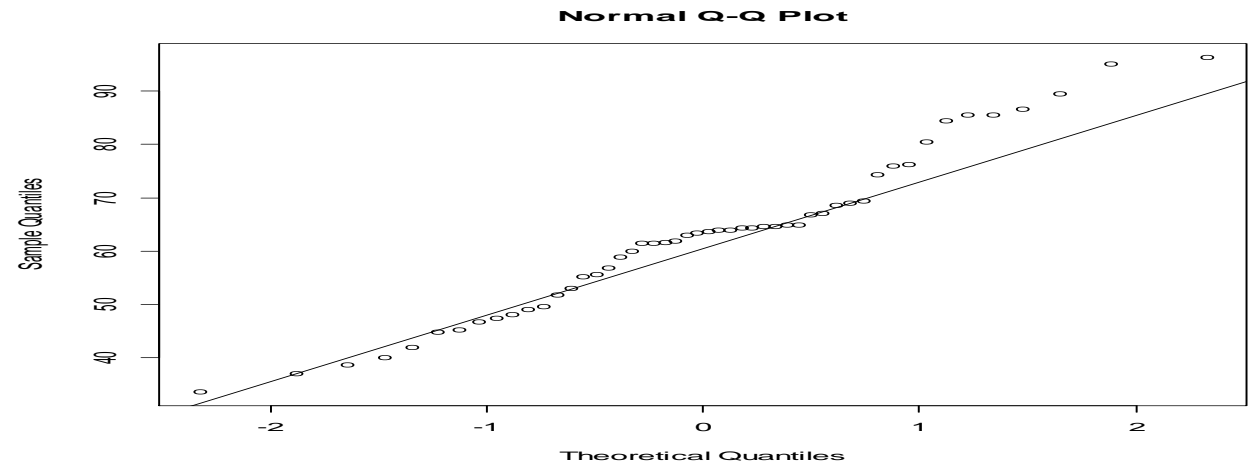

Fonte: Elaborado pelos pesquisadores com base nos dados coletados. 


\section{SHAPIRO WILK PARA O SISTEMA DE CLASSIFICAÇÃO TISS-28}

Figura 2 - Aplicabilidade do teste de Shapiro para os dados apresentados no Sistema de Classificação de Pacientes - TISS-28. Jacareí, 2021.

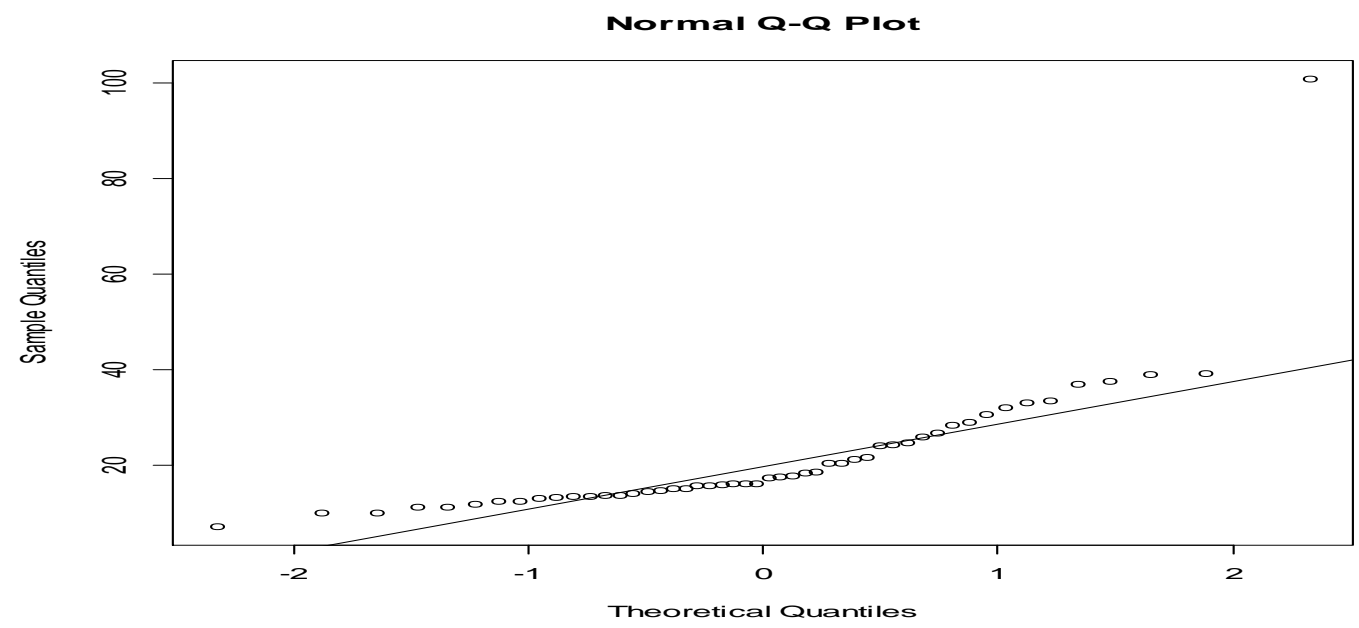

Fonte: Elaborado pelos pesquisadores com base nos dados coletados.

\section{SHAPIRO WILK PARA O SISTEMA DE CLASSIFICAÇÃO DE PACIENTES FUGULIN}

Figura 3 - Aplicabilidade do teste de Shapiro para os dados apresentados no Sistema de Classificação de Pacientes - Fugulin. Jacareí, 202r.

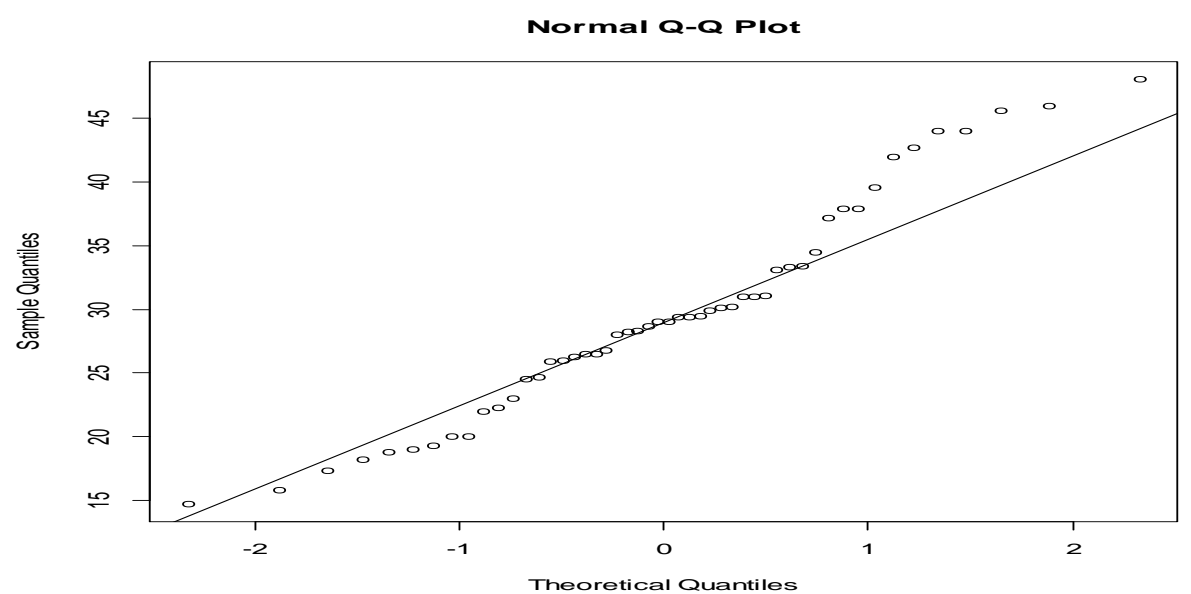

Fonte: Elaborado pelos pesquisadores com base nos dados coletados. 

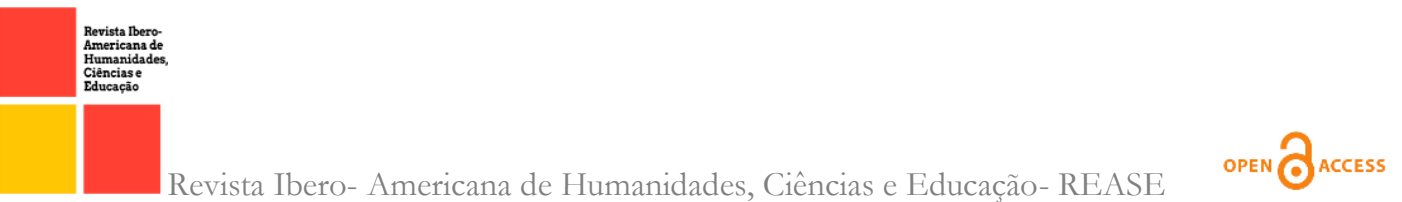

A partir da interpretação dos dados foi possível identificar que o NAS não se mostrou apropriado para utilização no âmbito do dimensionamento de pessoal para esta Unidade de Terapia Intensiva, visto que, no teste de normalidade, comparado com os demais instrumentos apresentou um $\mathrm{p}$-valor $=0,2393$, que se distancia do valor proposto de $5 \%$ (Figurar). O sistema de classificação de pacientes TISS-28 também não se apresentou como um instrumento adequado e sensível para o dimensionamento para esta Unidade de Terapia Intensiva, se afastando do padrão de normalidade. Tem-se como p-valor= r.or6e-og, conforme se vê na Figura 2.

De acordo com os dados apresentados e com o levantamento das informações obtidas no estudo, dentre os instrumentos, o Fugulin foi o mais sensível. Mediante aplicação do teste de normalidade de Shapiro Wilk, obteve como normalidade $\mathrm{p}$-valor $=0.1047$, aproximandose do padrão (Figura 3). De fato, entre os sistemas propostos, o Fugulin se apresentou mais sensível para a aplicação de dimensionamento de pessoas Unidade de Terapia Intensiva, cenário dessa pesquisa.

\section{RESULTADOS DA REVISÃO INTEGRATIVA}

A coleta de dados para a revisão integrativa da literatura foi realizada entre os meses de março a outubro de 2021. Com o cruzamento dos descritores foram encontradas 923 publicações e com a utilização dos critérios de inclusão/exclusão foram evidenciados 7 I estudos, sendo que $(n=55)$ estudos estavam indexados na base de dados da BDENF e $(n=16)$ indexados nas bases de dados da LILACS. Do total de estudos encontrados $(n=71)$, foram excluídos da base de dados da BDENF 2 estudos, pois, estavam duplicados e, a partir da leitura dos títulos dos estudos resultantes, foram selecionados para leitura flutuante 39 estudos, sendo eles da BDENF e LILACS. Da leitura flutuante foram escolhidos 25 artigos para a realização da leitura sistemática, a qual conduziu para a construção da amostra deste estudo $(n=23)$. Os demais estudos foram excluídos por não atender às questões norteadoras e os objetivos desse estudo. Portanto, a amostra desse estudo foi constituída por 23 publicações.

O Quadro I apresenta a caracterização da amostra $(n=23)$ de publicações selecionadas nas bases de dados para a composição do referencial teórico, trazendo as informações sobre 
as bases de dados, títulos das publicações, nomes dos autores e ano de publicação de acordo com o cruzamento dos descritores.

Quadro I - Caracterização da amostra $(n=23)$ de acordo com o cruzamento dos descritores nas bases de dados BDENF e LILACS que subsidiaram a construção do referencial teórico.

Mogi das Cruzes, 2021.

\begin{tabular}{|c|c|c|c|c|}
\hline \multicolumn{5}{|c|}{ Io Unidade de terapia intensiva and recursos humanos de enfermagem } \\
\hline № & $\begin{array}{l}\text { Base de } \\
\text { dados }\end{array}$ & Título do estudo & Autores & $\begin{array}{c}\text { Ano de } \\
\text { Publicação }\end{array}$ \\
\hline OI & BDENF & $\begin{array}{l}\text { Formação do Enfermeiro para os } \\
\text { cuidados de pacientes críticos na } \\
\text { Unidade de Terapia Intensiva }\end{array}$ & VERAS et al & 2019 \\
\hline 02 & BDENF & $\begin{array}{l}\text { Classificação de pacientes e carga de } \\
\text { trabalho } \\
\text { de enfermagem em terapia intensiva: } \\
\text { comparação entre instrumentos }\end{array}$ & FERREIRA et al & 2017 \\
\hline 03 & BDENF & $\begin{array}{c}\text { Fatores associados à carga de trabalho } \\
\text { de enfermagem em terapia intensiva: } \\
\text { Quais se devem considerar? }\end{array}$ & LAUS et al & 2017 \\
\hline 04 & BDENF & $\begin{array}{c}\text { Divergências entre legislações do } \\
\text { dimensionamento de Enfermagem } \\
\text { em } \\
\text { Unidades de Terapia Intensiva }\end{array}$ & RODRIGUES et al & 2017 \\
\hline \multicolumn{5}{|c|}{$\begin{array}{l}2^{\circ} \text { Cruzamento dos descritores: Assistência de enfermagem and unidade de terapia } \\
\text { intensiva de adulto }\end{array}$} \\
\hline 05 & BDENF & $\begin{array}{c}\text { Aplicação do Nursing Activities } \\
\text { Score (NAS) em uma } \\
\text { Unidade de Terapia Intensiva (UTI) }\end{array}$ & LOUREDO et al & 2021 \\
\hline 06 & BDENF & $\begin{array}{l}\text { Incidência da Síndrome de Burnout } \\
\text { em profissionais de Enfermagem } \\
\text { atuantes em Unidade de Terapia } \\
\text { Intensiva }\end{array}$ & SILVA et al & 2021 \\
\hline 07 & BDENF & $\begin{array}{l}\text { Necessidades humanas básicas em } \\
\text { terapia intensiva }\end{array}$ & SOUZA et al & 2019 \\
\hline 08 & BDENF & $\begin{array}{l}\text { Classificação de pacientes e } \\
\text { dimensionamento de profissionais de } \\
\text { enfermagem: contribuições } \\
\text { de uma tecnologia de gestão }\end{array}$ & $\begin{array}{l}\text { VANDRESEN et } \\
\text { al }\end{array}$ & 2018 \\
\hline \multicolumn{5}{|c|}{$\begin{array}{l}3^{\circ} \text { Cruzamento dos descritores: Assistência de enfermagem and segurança do paciente } \\
\text { and unidade de terapia intensiva }\end{array}$} \\
\hline 09 & BDENF & $\begin{array}{l}\text { Fatores associados à cultura de } \\
\text { segurança do paciente em unidades } \\
\text { de terapia intensiva }\end{array}$ & $\begin{array}{l}\text { KRUSCHEWSKY } \\
\text { et al }\end{array}$ & 2020 \\
\hline
\end{tabular}




\begin{tabular}{|c|c|c|c|c|}
\hline IO & BDENF & $\begin{array}{c}\text { Elaboração e validação de } \\
\text { instrumento de assistência de } \\
\text { enfermagem para pacientes em } \\
\text { unidades de terapia intensiva }\end{array}$ & FERREIRA et al & 2018 \\
\hline \multicolumn{5}{|c|}{$\begin{array}{c}4^{\circ} \text { Cruzamento dos descritores: Unidade de terapia intensiva and carga de trabalho and } \\
\text { enfermagem }\end{array}$} \\
\hline II & BDENF & $\begin{array}{c}\text { Dimensionamento do pessoal de } \\
\text { enfermagem na terapia intensiva } \\
\text { adulto }\end{array}$ & INOUE et al. & 2010 \\
\hline 12 & LILACS & $\begin{array}{l}\text { Nursing Activities Score (NAS): } \\
\text { adaptação transcultural e validação } \\
\text { para a língua portuguesa }\end{array}$ & $\begin{array}{l}\text { QUEIJO E } \\
\text { PADILHA }\end{array}$ & 2009 \\
\hline 13 & LILACS & $\begin{array}{l}\text { Sistemas de classificação de pacientes } \\
\text { como instrumento de gestão em } \\
\text { Unidades de Terapia Intensiva }\end{array}$ & $\begin{array}{l}\text { TRANQUITELLI } \\
\text { et al }\end{array}$ & 2007 \\
\hline \multicolumn{5}{|c|}{$5^{\circ}$ Cruzamento de descritores: Cuidados intensivos and índice de gravidade } \\
\hline 14 & LILACS & $\begin{array}{c}\text { Therapeutic intervention scoring } \\
\text { system-28 (TISS-28): diretrizes para } \\
\text { aplicação }\end{array}$ & PADILHA et al & 2005 \\
\hline \multicolumn{5}{|c|}{ 6o Cruzamento de descritores: Administração de pessoal and carga de trabalho } \\
\hline 15 & LILACS & $\begin{array}{l}\text { Sistema de classificação de pacientes: } \\
\text { identificação do perfil assistencial } \\
\text { dos pacientes das unidades de } \\
\text { internação do HU-USP }\end{array}$ & FUGULIN et al & 2005 \\
\hline \multicolumn{5}{|c|}{$7^{\circ}$ Cruzamento de descritores: Índice de gravidade de doença and cuidados intensivos } \\
\hline I6 & BDENF & $\begin{array}{l}\text { Aplicação do sistema de pontuação } \\
\text { de intervenções terapêuticas (TISS } \\
\text { 28) em unidade de terapia intensiva } \\
\text { para avaliação da gravidade do } \\
\text { paciente } \\
\end{array}$ & ELIAS et al & 2006 \\
\hline \multicolumn{5}{|c|}{$\begin{array}{l}\text { 80 Cruzamento de descritores: Recursos humanos de enfermagem no hospital and } \\
\text { assistência de enfermagem and avaliação em enfermagem }\end{array}$} \\
\hline I7 & LILACS & $\begin{array}{c}\text { Utilização de sistema de classificação } \\
\text { de pacientes e métodos de } \\
\text { dimensionamento de pessoal de } \\
\text { enfermagem }\end{array}$ & VIGNA et al & 2007 \\
\hline I8 & LILACS & $\begin{array}{l}\text { Sistema de classificação de pacientes; } \\
\text { proposta de complementação do } \\
\text { instrumento Fugulin et al }\end{array}$ & SANTOS et al & 2007 \\
\hline \multicolumn{5}{|c|}{ 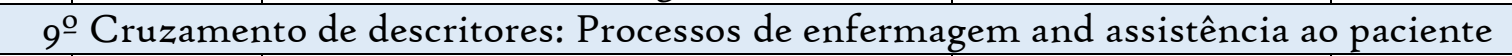 } \\
\hline I9 & BDENF & $\begin{array}{l}\text { A equipe de enfermagem frente ao } \\
\text { processo de implantação da } \\
\text { sistematização da assistência de } \\
\text { enfermagem }\end{array}$ & GIEH et al & 2016 \\
\hline
\end{tabular}




\begin{tabular}{|c|c|c|c|c|}
\hline 20 & BDENF & $\begin{array}{c}\text { Tradução para o português e } \\
\text { validação de um instrumento de } \\
\text { medida de carga de trabalho de } \\
\text { enfermagem em Unidade de Terapia } \\
\text { Intensiva: Nursing Activities Score } \\
\text { (N. A. S.) }\end{array}$ & QUEIJO & 2002 \\
\hline \multicolumn{5}{|c|}{$\begin{array}{c}\text { II - Cruzamento de descritores: Dimensionamento de equipe and Unidade de Terapia } \\
\text { Intensiva }\end{array}$} \\
\hline $2 \mathrm{I}$ & BDENF & $\begin{array}{c}\text { Dimensionamento do pessoal de } \\
\text { enfermagem na terapia intensiva } \\
\text { adulto }\end{array}$ & INOUE et al. & 2010 \\
\hline \multicolumn{5}{|c|}{$\begin{array}{l}\text { I2 } \text { - Cruzamento de descritores: Enfermagem and Avaliação em saúde and Carga de } \\
\text { trabalho and Classificação }\end{array}$} \\
\hline 22 & BDENF & $\begin{array}{l}\text { Sistema de classificação de pacientes } \\
\text { de FUGULIN: Perfil assistencial da } \\
\text { clínica médica }\end{array}$ & NOBRE et al. & 2017 \\
\hline \multicolumn{5}{|c|}{$\begin{array}{l}\text { 13을 Cruzamento de descritores: Carga de trabalho and unidade de terapia intensiva } \\
\text { adulto and enfermagem }\end{array}$} \\
\hline 23 & BDENF & $\begin{array}{l}\text { Dimensionamento de pessoal de } \\
\text { enfermagem na UTI - Adulto de } \\
\text { Hospital Universitário Público }\end{array}$ & BORGES et al. & 2017 \\
\hline
\end{tabular}

Fonte: Dados de pesquisa organizado pelas pesquisadoras.

\section{REFERENCIAL TEÓRICO}

\section{SISTEMA DE CLASSIFICAÇÃO DE PACIENTES}

O processo de trabalho de enfermagem em Unidade de Terapia Intensiva (UTI) é caracterizado por atividades assistenciais complexas que exigem alta competência técnica e científica - afinal, a tomada de decisões imediatas e adoção de condutas seguras estão diretamente relacionadas à vida e à morte de pessoas (INOUE; MATSUDA, 20ı).

Nesse contexto, é notório que a carga de trabalho dos profissionais de enfermagem na UTI é um grande desafio para os gestores para a realização de um dimensionamento de profissionais para uma assistência segura, eficaz e embasada em técnicas e evidências cientificas (FERREIRA et al., 2017).

Entende-se como dimensionamento de pessoal, um processo sistemático que tem por finalidade a previsão da quantidade e qualidade por categoria (enfermeiro, técnico e auxiliar de enfermagem) necessária para atender, direta ou indiretamente, às necessidades de assistência de enfermagem da clientela. Em UTI, o dimensionamento do pessoal de 

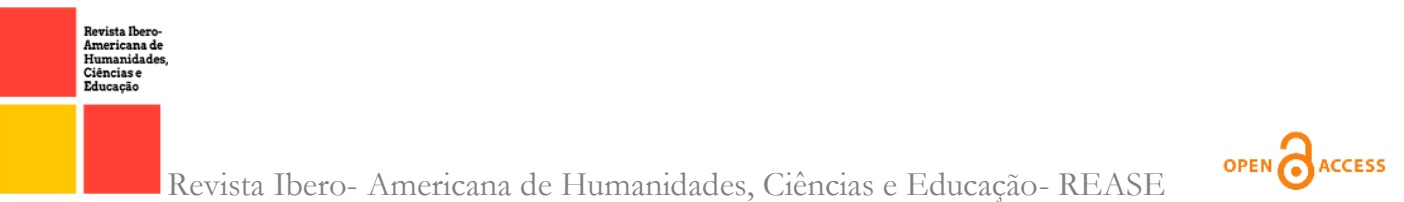

enfermagem, além de suprir à demanda de cuidados requerida pelos pacientes, contribui para que sejam mantidas condições favoráveis de trabalho e, consequentemente, a saúde dos trabalhadores de enfermagem que lidam diariamente com situações estressantes - o sofrimento e a morte (INOUE; MATSUDA, 2010).

Para avaliar a carga de trabalho de enfermagem são utilizados instrumentos e ferramentas para obtenção de horas de cuidado, necessárias para fundamentar o dimensionamento de profissionais de enfermagem. É utilizado o Sistema de Classificação de Pacientes (SCP), que estima as horas de cuidados deverão ser desempenhadas, conforme a complexidade assistencial do paciente O Conselho Federal de Enfermagem (COFEN), estabelece normativas para o dimensionamento de pessoal com a utilização de SCP (Sistema de Classificação de Pacientes). A diretriz está na Resolução I89/1996, atualizada pela Resolução 293/2004, e substituída atualmente pela 0527/2016 alterando o número de horas de assistência de enfermagem nas 24 horas, reformulando em categorias de cuidado, e institui a alta dependência como mais uma categoria (FERREIRA et. al., 2017; VANDRESEN et al. 2018).

O SCP por grau de dependência subsidia ferramentas para os cálculos de dimensionamento de Enfermagem, também, proporciona o cuidado de forma centrada no indivíduo. Os cálculos de dimensionamento são cruciais para o planejamento da assistência, o desenvolvimento de recursos de informática e programas computacionais para a realização desta prática é altamente eficaz e agiliza o processo de tomada de decisões. O enfoque assistencial voltado aos problemas no âmbito individual, pressupõe-se que as unidades de cuidados devam ser adequadas às necessidades da clientela atendida. Além disso, é necessário um dimensionamento de equipe com base na classificação de risco do paciente, proporcionando uma qualidade na assistência. Isto irá proporcionar uma mensuração na carga de trabalho da equipe. (VANDRESEN et al., 2or8; INOUE; MATSUDA, 2ого).

Com base no exposto, é importante considerar que, em UTI, geralmente, estão alocados pacientes extremamente debilitados e com maior dependência de cuidados do que em outras unidades hospitalares, e por esta razão, o dimensionamento do pessoal de enfermagem deve ser estimado mediante o uso de instrumentos mais completos e de fácil aplicação que considerem as diversas atividades desenvolvidas especificamente neste setor 

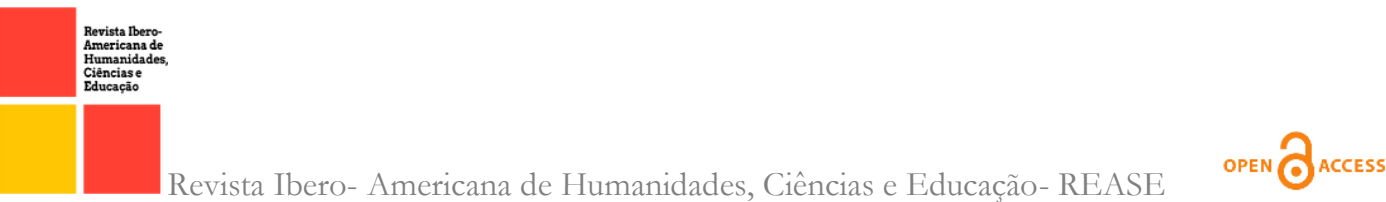

e auxiliem na real quantificação da carga de trabalho da enfermagem e na determinação do número de trabalhadores para compor a equipe (INOUE; MATSUDA, 20Io).

Conforme Padilha et al. (2005) o SCP TISS-28 é um instrumento metodológico extremamente útil e eficaz para o processo de assistência do paciente e dimensionamento de trabalho da equipe de enfermagem. Possui funcionalidade direta na classificação da patologia do paciente, baseando-se em princípios intervencionistas e condições clínicas.

Portanto, quanto maior a criticidade, maior será o valor do score e tempo demando de assistência ao cuidado. O TISS-28 também permite avaliar a carga de trabalho da equipe de enfermagem em Unidade de Terapia Intensiva, pois, para cada ponto atribuído ao TISS28 são consumidos "iо,6 minutos do tempo de trabalho de um profissional da equipe de enfermagem na assistência ao doente crítico" (PADILHA et al, 2005, pag. 230).

De acordo com Padilha et al. (2005) para otimização do processo, o instrumento de SCP deve ser utilizado conforme análise crítica do paciente e julgamento clínico de enfermagem, conforme as categorias e itens avaliados do instrumento TISS-28, sendo 28 itens divididos em 5 grupos de intervenções: I) Atividades básicas; 2) suporte ventilatório; 3) suporte cardiovascular; 4) suporte renal; 5) suporte neurológico; 6) suporte metabólico e, 7) intervenções específicas. Cada item traz uma relação de subitens que designam tempo de cuidado assistencial.

Conforme descrito por Elias et al. (2006), cada um dos itens que compõem o instrumento TISS-28 recebe uma pontuação que varia de um (I) a oito (8) pontos e a somatória classifica o paciente em quatro (4) possibilidades de necessidades de cuidados intensivos, denominadas classes: classe I (escore entre o a 19 pontos - pacientes fisiologicamente estáveis que requerem atenção para prevenção de complicações); Classe II (escore entre 20 a 34 pontos - se caracterizam como pacientes estáveis, porém, requerem cuidados intensivos da enfermagem e a monitoramento contínuo); Classe III (escore entre 35 a 60 pontos - são caracterizados como pacientes graves e instáveis hemodinamicamente, requerendo cuidados mais intensivos e vigilância constante da enfermagem); Classe IV (escore maior que 6o pontos - são pacientes graves, instáveis que requerem assistência da equipe de enfermagem e multiprofissional contínua e especializada, o que demanda maior tempo de atenção da enfermagem). 

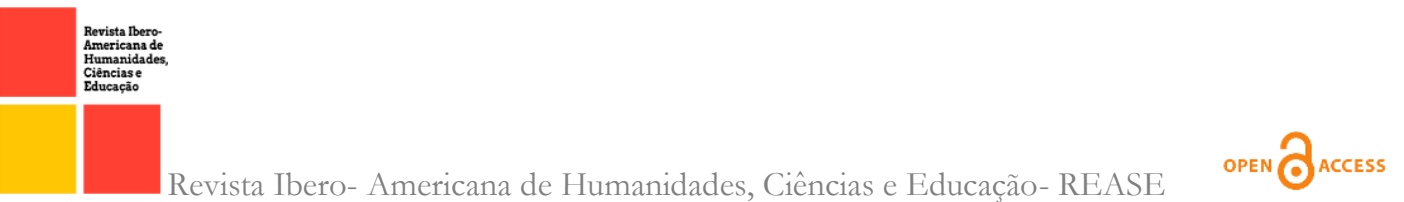

Segundo Louredo et al. (2021) o SCP Nursing Activities Score (NAS) é um instrumento diferencial para a classificação de paciente, que visa medir a real carga de trabalho de enfermagem e o tempo de assistência de enfermagem aos pacientes internados na UTI.

Queijo e Padilha (2009) descrevem que o instrumento foi elaborado por meio da modificação do TISS-28, resultando em um instrumento metodológico de SCP composto por sete (7) categorias que avaliam 23 itens, correspondentes as atividades de enfermagem, e a pontuação de cada item por variar entre 1,2 pontos (pontuação mínima) e 32,0 pontos (pontuação máxima), e a somatória dos escores deste instrumento é no máximo i76,8 pontos. Araújo et al (2012) descreve que, cada ponto do instrumento NAS corresponde a 14,4 minutos de trabalho prestado pela equipe de enfermagem e que, quanto maior for esta pontuação, maior será a necessidade de profissional de enfermagem no período de 24 horas, sendo que a cada roo pontos obtidos será previsto um profissional de enfermagem por turno.

Para aplicação do NAS, considera-se o quadro crítico que o paciente apresentou nas 24 horas, além de poder ser aplicado em cada turno no mesmo horário. Vale ressaltar, que quando pontuado em cada turno não deverá ser a média de ambos e sim, a pontuação maior e, a partir da obtenção do escore de cada paciente, o enfermeiro deverá somar os escores de todos os pacientes da Unidade de Terapia Intensiva para realizar os cálculos de dimensionamento de pessoal. (QUEIJO e PADILHA, 2009; ARAÚJO et al., 2012; LAUS et al., 2017).

A carga de trabalho é um elemento crucial para dimensionar os profissionais, subsidiando a determinação de práticas assistências que visem uma assistência qualificada, proporcionando tanto ao paciente tranquilidade ao cuidado realizado e ao profissional um ambiente favorável a se trabalhar (FERREIRA, 2017).

Para Borges et al. (2017) os fatores associados à sobrecarga de trabalho da equipe de enfermagem em UTI estão associados à fatores de risco ao desenvolvimento de infecções lesões por pressão e erros de medicação, além de outros recursos relacionados a gestão pessoal como absenteísmo e elevada rotatividade. Conforme a Resolução vigente do COFEN é recomendado que a equipe de enfermagem realize assistência ao paciente de cuidado intensivo sendo composta por $52 \%$ de enfermeiros. 


\section{SISTEMA DE CLASSIFICAÇÃO DE PACIENTES: FUGULIN}

O SCP, segundo a escala de Fugulin, remete-se a avaliação de pacientes quanto ao grau de dependência da equipe de enfermagem, determinando o perfil do grau de dependência quanto aos cuidados, obtendo a seguinte classificação: cuidados mínimos (C. Min.), cuidados intermediários (C. Interm.), cuidados de alta dependência (CAD), cuidados semi-intensivo (CSI) e cuidados intensivos (C. Intens.). Esta classificação permite direcionar o planejamento do dimensionamento do quadro de pessoal de enfermagem e assistência ao paciente (SANTOS et al., 2007).

De acordo com Santos et al. (2007) o instrumento de Fugulin tem a finalidade de classificar o paciente defronte à sua dependência à equipe de enfermagem. Além de fornecer insumos necessários para o dimensionamento de enfermagem para as unidades assistenciais, como os dados de horas de trabalho da equipe de enfermagem e a relação quanti-qualitativa do quadro de pessoal necessário para atender as demandas do cuidado ao paciente frente às suas necessidades humanas básicas afetadas (biopsicossociais e espirituais).

O Sistema de Classificação de Pacientes de Fugulin é composto por nove áreas do cuidado sendo: estado mental, oxigenação, sinais vitais, alimentação, motilidade, deambulação, cuidado corporal, eliminação, terapêutica. Mediante análise realizada do paciente será lançado scores de um a quatro, e a partir da somatória destes escores pode variar entre 12 a 48 , indicando de forma crescente a complexidade assistencial do paciente. Diante disto, a seguintes classificações: cuidado mínimo (I2 a 17 score); cuidado intermediário (I8 a 22 score); alta dependência (23 a 28 score); cuidado semi-intensivo (29-34 score) para subsidiar o dimensionamento dos profissionais de enfermagem (NOBRE, 2017).

Um estudo de identificação do perfil assistencial de pacientes do HU-USP cita que o SCP Fugulin requer ajustes e adaptações para implantação nas divergentes unidades de uma instituição, a partir de uma análise das características dos pacientes. Conforme as autoras, o Fugulin pode ser aplicado em Unidades de Terapia Intensiva. Porém, o instrumento não é capaz de descrever os níveis de complexidade dos pacientes internados na UTI. As mesmas sugerem que deve ser analisado e proposto a utilização de um instrumento mais especifico para a unidade, o TISS (Terapeutic Intervention Scoring System), que permita verificar o nível de gravidade do paciente, o número de intervenções 
realizadas e, a partir disso, designar o tempo de assistência de enfermagem que será oferecida (FUGULIN et al., 2005).

\section{DINÂMICA DE TRABALHO EM UMA UNIDADE DE TERAPIA INTENSIVA}

Para Souza et al. (2019) a Unidade de Terapia intensiva exige uma qualificação profissional com um maior preparo técnico científico, pois é uma unidade que concentra profissionais especializados, uma variada gama de recursos tecnológicos sofisticados e de alto custo. Os profissionais devem obter conhecimento especializado e habilidades diferenciadas adquiridas no momento da graduação.

A assistência direta ao paciente critico é privativo do profissional enfermeiro, o técnico de enfermagem tem como função assistir o enfermeiro na prestação de cuidados, conforme o artigo ıo ${ }^{\circ}$ inciso I alínea b do Decreto Lei 94406 de o8 de junho de 1987. Conforme a Resolução COFEN 543/2017, estabelece que a distribuição percentual de enfermeiros para assistência de pacientes críticos deve corresponder a 52\% do total calculado. Por ser uma atividade privativa do enfermeiro, o número de enfermeiros deve ser superior ao de técnicos de enfermagem na Unidade de Terapia Intensiva (BRASIL, 1986; COFEN, 2017).

Conforme Vandresen et al. (2018) a classificação de pacientes é um instrumento indispensável para o planejamento e organização da assistência focado no usuário e dimensionar os profissionais de enfermagem. É necessário ser realizada de forma diária e sistemática, a classificação reflete, a uma estimativa de cuidados que será desempenhado a cada indivíduo.

Para que a recuperação do paciente ocorra da melhor forma, no menor tempo possível, vários cuidados podem ser prestados por toda equipe dentro de uma unidade de terapia intensiva, podem se listar separadamente a dinâmica de como devem ocorrer, tais como citados por PADILHA et al. (20II): higiene e contorto; atividades físicas; segurança física; nutrição e hidratação; oxigenação e ventilação; eliminações; utilização de equipamentos e, unidade de terapia intensiva. Cada um com seus subitens a serem avaliados mediante necessidade do paciente.

A qualidade de vida no trabalho é essencial para um bom desempenho da atividade realizada, em contrapartida é uma das maiores preocupação para as equipes de enfermagem que atuam em Unidade de Terapia Intensiva. Tornou-se notório em estudos que os 

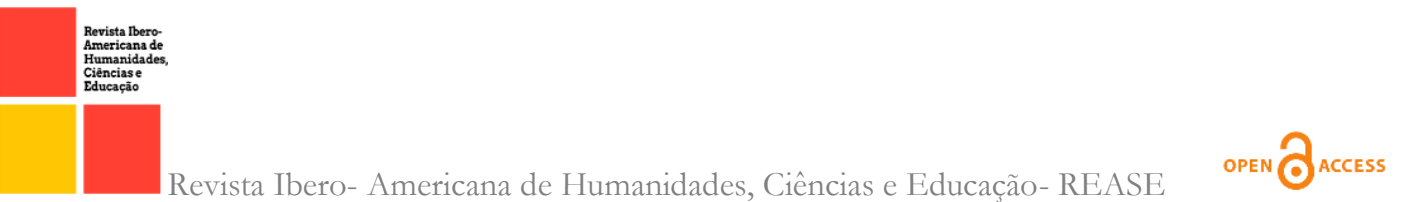

enfermeiros que trabalham com cuidados críticos possuem maior predisposição ao estresse, enquanto outros estudos mostram que a sobrecarga de trabalho e os problemas interpessoais apresentam-se com os estressores mais evidentes entre os enfermeiros da UTI. (Silva et al., 202I)

\section{EDUCAÇÃO CONTINUADA}

\section{a) Educação Sobre Sistematização da Assistência de Enfermagem}

Para Ferrari et al. (2016), neste contexto, a Sistematização da Assistência de Enfermagem (SAE), é caracterizada como um modelo científico que norteia a pratica assistencial, contribuindo para a efetividade do cuidado, segurança do paciente e melhorias continua nas execuções dos processos gerenciais e de cuidados. A implantação nas instituições tem como caráter organizar o modelo assistencial com embasamento de métodos sistemáticos proporcionando para o profissional um olhar holístico para o desempenho de suas atividades.

A implantação e implementação da SAE nas instituições de saúde segue o molde da direcionados pelo $\mathrm{PE}$, pelo qual a equipe de enfermagem realiza o cuidado de forma sistematizada e ordenada em princípios científicos e comprovados por práticas clinicas. $\mathrm{O}$ Processo de Enfermagem (PE) é constituído por 5 etapas inter-relacionadas sendo elas; coleta de dados de enfermagem, diagnósticos de enfermagem, planejamento de enfermagem, implementação e avaliação de enfermagem (FERRARI et al., 20I6).

Conforme Giehl et al. (2016), foi identificado que há algumas dificuldades encontradas na aplicabilidade da SAE no dia a dia institucional como; sobrecarga de trabalho e por consequência a falta de tempo para o preenchimento, déficit no dimensionamento de profissionais de enfermagem, excesso de cobranças burocráticas e ausência de treinamentos para aperfeiçoar os profissionais quanto as utilizações dos instrumentos. A correta utilização da SAE como um instrumento que norteia a assistência e as devidas tomadas de decisões no âmbito do cuidado, faz-se necessárias capacitações, atualizações e supervisão da educação continuada na equipe de enfermagem.

\section{b) Educação Continuada Sobre Sistema de Classificação De Pacientes}

Conforme Oliveira et al. (2019) a formação permanente do enfermeiro na UTI não se limita a titulação lato ou stricto sensu, é de suma importância a capacitação profissional 
recorrente através de educação continuada e permanente para uma construção de práticas baseadas em evidências. Desta forma, os programas de capacitação no ambiente hospitalar são essenciais para buscar estratégias que não atenda somente as necessidades pessoais, mas às profissionais, da instituição, do cliente e da sociedade.

O Sistema de Classificação de Pacientes (SCP) foi proposto para avaliar e classificar o paciente quanto a função da demanda de cuidado. O Conselho de Enfermagem determina que para o dimensionamento de enfermagem utiliza-se uma escala com pontuação que irá classificar os clientes em quatro tipos de cuidado, a partir da carga de trabalho (RODRIGUES et al., 2017)

A Resolução № ı89/96 COFEN, atualmente revogada pela Resolução COFEN no 543/2017, fundamenta o cálculo de pessoal de enfermagem que determina que aplicação da SCP como um dos indicadores para determinar o perfil de clientes nas instituições hospitalares, tendo como características as horas para assistência e o dimensionamento de enfermagem para cada tipo de cuidado a ser realizado (VIGNA et al., 2007).

De acordo com Cardoso et al. (2018) as instituições de saúde têm incorporado novas metodologias para de capacitação e treinamento contínuos, valorizando a importância do ensino-aprendizagem no ambiente de trabalho, proporcionando uma qualidade assistencial adequada. A formação continuada dos profissionais de saúde é essencial para construção do conhecimento e autonomia para manusear instrumentos e novas tecnologias inseridas nas instituições. A educação continuada em serviço são práticas desenvolvidas, que contribui de forma significativa para transformação pessoal e profissional. São estratégias educativas focadas em raciocínio lógico e alternativas diversas para reduzir dificuldades no ambiente de trabalho.

\section{DISCUSSÃO}

Para Padilha et al. (2005) e, de acordo com a hipótese desse estudo, o SCP TISS-28 é um instrumento metodológico extremamente útil e eficaz para o processo de assistência do paciente e dimensionamento de trabalho da equipe de enfermagem na Unidade Terapia Intensiva, possuindo funcionalidade direta na classificação da patologia do paciente, baseando-se em princípios intervencionistas e condições clínicas. Contudo, o resultado esperado era que esse instrumento apresentasse maior sensibilidade em comparação aos 
outros incluídos (Fugulin e NAS). No entanto, ele não se mostrou adequado para aplicação na unidade onde o estudo foi realizado.

Diante da avaliação dos resultados obtidos, observou-se que o instrumento mais sensível ao Serviço de Enfermagem, subsidiando o processo de dimensionamento de pessoas na Unidade de Terapia Intensiva é o instrumento Fugulin, apresentando o p-valor mais próximo do padrão do teste de normalidade aplicado.

De acordo com o instrumento de SCP Fugulin, utilizado para a classificação da complexidade assistencial dos pacientes na UTI, a média dos escores obtidos foi 29 (Tabela 2) e, esta pontuação classifica o paciente em cuidados semi-intensivos. A UTI, cenário deste estudo, possui ro leitos e, em função da pandemia causada pelo novo coronavírus, não possível realizar a coleta de dados em um único mês, como o proposto no projeto inicial, o que impactou no resultado frente à média de internação/mês.

Desta forma, não foi possível a realização do cálculo de dimensionamento de pessoal, de forma pontual, utilizando o SCP Fugulin, no entanto, tem-se a média da classificação dos pacientes (prontuários) avaliados e, a utilização do teste de Shapiro para a confirmação da normalidade.

De acordo com o dimensionamento de Fugulin, tem-se cuidados mínimos (12-17), 3 pacientes; cuidados intermediários (18-22), 8 pacientes; cuidados de alta dependência (23-28), 12 pacientes; cuidados semi-intensivos (29-34), i7 pacientes e cuidados intensivos (acima de 34), io pacientes.

Partindo desta amostra, a Resolução COFEN no 543/2017 apresenta o cálculo de dimensionamento que é baseado no total de horas de enfermagem (THE) vezes a KM, constante marinho $(\mathrm{KM}=\mathrm{DS} \times \mathrm{IST} / \mathrm{JST})$ sendo, $\mathrm{DS}=$ Dias da semana, IST = Índice de Segurança Técnico e JST = Jornada Semanal de Trabalho.

Segundo Inoue (2010) O dimensionamento do pessoal de enfermagem, portanto, fundamenta o planejamento e a avaliação do quantitativo e qualitativo de pessoal para prover cuidados de enfermagem que garantam a qualidade, previamente estabelecida, a um grupo de pacientes, de acordo com a filosofia, a estrutura da instituição e, também, com a singularidade de cada serviço. Vale ressaltar que tanto o ECA, citado pelos enfermeiros como SCP, e o Fugulin se traduzem no mesmo instrumento de classificação de pacientes, no entanto, há necessidade de se avaliar qual versão do instrumento de SCP está sendo 
utilizado na UTI para a classificação dos pacientes. Outro detalhe a ser avaliado é o uso da metodologia para o cálculo de dimensionamento, pois, atualmente é baseado na Resolução COFEN 543/2017 que traz um aumento significativo de horas de trabalho para cada nível de complexidade assistencial para a realização do cálculo quantitativo de pessoal.

A Resolução COFEN 543/2017, também, estabelece que a distribuição percentual de enfermeiros para assistência de pacientes críticos deve corresponder a 52\% do total calculado, e os demais são compostos por técnicos de enfermagem. Por ser uma atividade privativa do enfermeiro, o número de enfermeiros deve ser superior ao de técnicos de enfermagem na Unidade de Terapia Intensiva.

Os cálculos de dimensionamento de pessoas são cruciais para a organização e planejamento assistência, o desenvolvimento de recursos de informática e programas computacionais para a realização desta prática é altamente eficaz e agiliza o processo de tomada de decisões dos profissionais de enfermagem (VANDRESEN et al., 2018; FUGULIN et al. 2005; SOUZA et al., 2019; PADILHA et al., 2011; SILVA et al., 202I).

Desta forma, salienta-se que é de suma importância que haja devida capacitação do enfermeiro acerca da utilização do instrumento de classificação de pacientes mais sensível, bem como a realização dos cálculos de dimensionamento de pessoal na UTI adulto (FERRARI et al., 2016; CARDOSO et al., 2018; GIEL et al., 2016; OLIVEIRA et al, 2019; RODRIGUES et al., 2017; VIGNA et a., 2007).

\section{CONSIDERAÇÕES FINAIS}

No contexto das questões norteadoras, que guiaram esse estudo, pode-se inferir que todas as questões foram respondidas. No período da coleta de dados, entre os sistemas de classificação de complexidade assistencial propostos para avaliação, o SCP Fugulin se apresentou como o mais sensível para a classificação dos pacientes mediante o Teste Shapiro Wilk (com normalidade $\mathrm{p}$-valor $=0.1047)$.

Mediante os escores obtidos na análise dos 50 prontuários, no SCP Fugulin a classificação média da complexidade assistencial ficou em 29 pontos. Tal resultado classificaria os pacientes em necessidades de cuidados semi-intensivos, no entanto, essa amostra não representa, na totalidade, o perfil de classificação de complexidade assistencial dessa UTI, em razão da coleta de dados não ter sido realizada de forma sistemática em um 
período contínuo. Contudo, a UTI já utiliza esse sistema de classificação, segundo os dados apontados pelos enfermeiros.

Ao responder as questões norteadoras, foi possível testar e rebater a hipótese desse estudo, onde se acreditava que o instrumento de Sistema de Classificação de Pacientes TISS-28 (Therapeutic Intervention Scoring System) se apresentaria como o instrumento mais sensível para atender as necessidades de cuidados dos pacientes internados na Unidade de Terapia Intensiva dessa Instituição de Saúde.

Para aplicabilidade do SCP Fugulin com legitimidade à realidade apresentada pelo perfil de pacientes classificados por esse estudo, há a necessidade de saber se o instrumento de Fugulin utilizado pela UTI está adequadamente atualizado para atendimento dos requisitos propostos pela Resolução COFEN 543/2017 que dispõe sobre o dimensionamento de pessoal.

Tais resultados subsidiaram a construção de um instrumento de SCP Fugulin no formato de formulário, atualizado, que será proposto para a Unidade de Terapia Intensiva da Instituição de Saúde, cenário desse estudo. Tal proposta será apresentada à Gerente de Enfermagem e, se aprovada, as pesquisadoras irão apresentar o instrumento ao grupo de enfermeiros da UTI com o propósito de orientar o seu preenchimento e somatório dos escores. Tal procedimento se justifica pelo fato de os enfermeiros apontarem o uso de instrumentos diferentes de SCP na UTI, de acordo com os resultados obtidos.

No entanto, o estudo traz alguns vieses, como o período de coleta de dados que foi impactado pela pandemia causada pelo novo coronavírus, pois, no mês de março de 2020 foram instituídas as regras de isolamento social e a mudança no cenário de atendimento na Instituição de Saúde, local da coleta dos dados. Nesse cenário, a coleta de dados foi realizada em períodos aleatórios, primeira etapa entre os meses de março a setembro de 2020 e, no segundo momento entre os meses de abril a maio de 2021, com essa irregularidade no período de coleta de dados e, na alteração no cenário do perfil de atendimento, os dados referentes ao perfil de atendimento podem não representar o verdadeiro perfil epidemiológico da unidade, necessitando de outros estudos com maior rigor neste critério (tempo de coleta de dados). Outro viés, o isolamento social que impossibilitou um maior contato com os familiares dos pacientes internados na UTI e enfermeiros entre os pesquisadores para melhor discussão dos dados obtidos. 
Portanto, sugere-se que outros estudos, nessa linha metodológica, sejam realizados para resolutividade desses vieses e obtenção de dados mais fidedignos de forma a identificar o perfil epidemiológico de atendimento da Unidade de Terapia Intensiva e avaliar de maneira mais pontual um SCP que seja sensível para a realidade local.

\section{REFERÊNCIAS BIBLIOGRÁFICAS}

ARAÚJO, Thamiris Ricci de. et al. Nursing Activities Score (NAS): proposta Nursing Activities Score (NAS): proposta de implantação no centro de terapia de implantação no centro de terapia intensiva. Revista Qualidade HC. n. 3, dezembro, 2012. Disponível em: 〈https://www.hcrp.usp.br/revistaqualidade/uploads/Artigos/105/I05.pdf〉.

BORGES, Fabieli et al. Dimensionamento de pessoal de enfermagem na UTI-Adulto de hospital universitário público. Cogitare Enfermagem, [S.1.], v. 22, n. 2, jun. 2017. ISSN 21769133. Disponível em: 〈https://revistas.ufpr.br/cogitare/article/view/50306〉. Acesso em: 20 nov. 202I.

BRASIL. Presidência da República. Decreto no 94.406, de 08 de junho de 1987. Regulamenta a Lei $\mathrm{n}^{\mathrm{o}} 7.498$, de 25 de junho de 1986, que dispõe sobre o exercício da enfermagem, e dá outras providências. Disponível em: http://www.planalto.gov.br/ccivil_03/decreto/ı98o1989/d94406.htm.

BRITO, Ana Paula de; GUIRARDELLO, Edinêis de.Nível de complexidade assistencial dos pacientes em uma unidade de internação. Revista Brasileira de Enfermagem [online]. 2012, v. 65, n. I, pp. 92-96. Disponível em: 〈https://doi.org/ı.1590/Soo34-71672012000100o13〉. Epub 26 Jun 2012. ISSN 1984-0446. Acesso em: 30 nov. 2021.

CAMELO, Silvia Helena Henriques. Competência profissional do enfermeiro para atuar em Unidades de Terapia Intensiva: uma revisão integrativa. Rev. Latino-Am. Enfermagem, Ribeirão Preto, v. 20, n. I, p. 192-200, fev. 2012. Disponível em 〈http://www.scielo.br/scielo.php?script=sci_arttext\&pid=Soro4II69201200o100025\&lng=pt\&nrm=iso $>$. Acesso em I2 abr. 2019. CARDOSO, R. B.; PALUDETO, S. B.; FERREIRA, B. J. Programa de educação continuada voltado ao uso de tecnologias em saúde: percepção dos profissionais de saúde. Revista Brasileira de Ciências da Saúde, [S. l.], v. 22, n. 3, p. 277-284, 2018. DOI: 10.22478/ufpb.2317- 
$6032.2018 \mathrm{v} 22 \mathrm{n} 3.35054$

Disponível

em:

https://periodicos.ufpb.br/ojs2/index.php/rbcs/article/view/35054. Acesso em: 13 out. 202I. COFEN. Conselho Federal de Enfermagem. Resolução no 358 de is de outubro de 2009. Dispõe sobre a Sistematização da Assistência de Enfermagem e a implementação do Processo de Enfermagem em ambientes, públicos ou privados, em que ocorre o cuidado profissional de Enfermagem, e dá outras providências. Disponível em: 〈http://www.cofen.gov.br/resoluo-cofen-3582009_4384.html〉. Acesso em 30 abr. 2019.

COFEN. Conselho Federal de Enfermagem. Resolução no 543 de 19 de abril de 2017. Atualiza e estabelece parâmetros para o Dimensionamento do Quadro de Profissionais de Enfermagem nos serviços/locais em que são realizadas atividades de enfermagem. Disponível em: $<$ http://www.cofen.gov.br/wpcontent/uploads/2017/o5/RESOLU\% $\mathrm{C}_{3} \% 87 \% \mathrm{C}_{3} \% 83 \mathrm{O}-\mathrm{COFEN-N} \% \mathrm{C}_{2} \% \mathrm{BA}-543-2017$ completa.pdf $>$. Acesso em 30 abr. 2019.

ELIAS, Adriana Cristina Galbiatti Parminondi; MATSUO, Tiemi; CARDOSO, Lucienne Tibery Queiroz; GRION, Cintia Magalhães Carvalho. Aplicação do Sistema de Pontuação de Intervenções Terapêuticas (TISS 28) em Unidade de Terapia Intensiva para Avaliação da Gravidade do Paciente. Rev Latino-am Enfermagem. v. I4, n. 3, pag. 324-329, maio-jun, 2006. Disponível em: 〈https://www.scielo.br/pdf/rlae/vi4n3/vi4n3ao4.pdf $>$. Acesso em 30 abr. 2019 .

FERRARI, Diego et al. A visão da equipe de enfermagem sobre a Sistematização da Assistência de Enfermagem em um hospital de médio porte. Revista Caderno Pedagógico, [S.1.], v. I3, n. 3, dez. 2016. ISSN 1983-0882. Disponível em: 〈http://univates.br/revistas/index.php/cadped/article/view/II6o〉. Acesso em: I2 out. 202I. FERREIRA, Patrícia Cabral et al . Classificação de pacientes e carga de trabalho de enfermagem em terapia intensiva: comparação entre instrumentos. Rev. Gaúcha Enferm., Porto Alegre , v. 38, n. 2, e62782, 2017 . Disponível em $<$ http://www.revenf.bvs.br/scielo.php?script=sci_arttext\&pid=Sig83I4472017000200405\&lng=pt\&nrm=iso $>$. acessos em 02 nov. 2021. Epub 29-Jun-2017. FUGULIN, Fernanda Maria Togeiro, et. al. Nursing care time in the Intensive Care Unit: evaluation of the parameters proposed in COFEN Resolution № 293/o4. Rev. Latino-Am. Enfermagem, v. 20, n.2, mar./abr. 2012 \{9 telas]. Disponível em < 


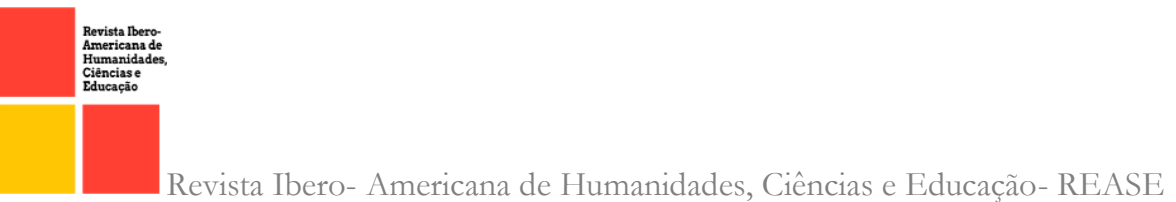

https://www.scielo.br/j/rlae/a/gRcpQ832DjHtfmvsS5gyZzqC/?lang=pt\&format=pdf . Acesso em 30 abr. 2019.

FUGULIN, Fernanda Maria Togeiro, et. al. Sistema de classificação de pacientes: identificação do perfil assistencial dos pacientes das unidades de internação do HU-USP. Revista Latino-Americana de Enfermagem [online]. 2005, v. 13, n. I, pp. 72-78. Disponível em: <https://doi.org/10.1590/So104-I169200500o10oor2〉. Acesso em 03 Out. 2021.

GIEHL, Carline et al. A equipe de enfermagem frente ao processo de implantação da Sistematização da Assistência de Enfermagem. Revista de Enfermagem e Atenção a Saúde, v. 5 n. 2, dez. 2016. ISSN 2317-II5. Disponível em: 〈http://seer.uftm.edu.br/revistaeletronica/index.php/enfer/article/view/r62r >Acesso em: I2 out. 202I.

HSFA. Hospital São Francisco de Assis. Unidades Estratégicas de Serviços - UNES. Disponível em: 〈https://www.hospitalsaofrancisco.org.br/servicos/adulto〉. Acesso em: or dez. 202I.

INOUE, Kelly Cristina; MATSUDA, Laura Misue Dimensionamento de pessoal de enfermagem em Unidade de Terapia Intensiva para adultos. Acta Paulista de Enfermagem [online]. 2010, v. 23, n. 3 [Acessado 2 Novembro 2021] , pp. 379-384. Disponível em: 〈https://doi.org/10.1590/Sor03-21002010000300011〉. Epub 29 Jul 2010.

LAUS, Ana Maria et al. Fatores associados à carga de trabalho de enfermagem em terapia intensiva: quais se devem considerar? Revista de Enfermagem UFPE on line, [S.1.], v. II, n. I2, p. 5305-53II, dez. 2017. ISSN 198I-8963. Disponível em: 〈https://periodicos.ufpe.br/revistas/revistaenfermagem/article/view/22847/25484〉. Acesso em: 02 nov. 2021.

LOUREDO PEREIRA, B. da S.; PEREIRA, S. R. M.; DE FARIAS, A. M. M.; BRIDI, A. C.; DE PAULA, V. G.; DE SOUZA, K. A. Aplicação do nursing activities score (NAS) em uma unidade de terapia intensiva (UTI). Revista de Pesquisa Cuidado é Fundamental Online, [S. 1.], v. I2, p. 79-87, 2021. DOI: 10.9789/2175-5361.rpcfo.vi2.7052. Disponível em: http://seer.unirio.br/cuidadofundamental/article/view/7052. Acesso em: 2 nov. 202I MINAYO, Maria Cecílica de Souza. O desafio do conhecimento: pesquisa qualitativa em saúde. 7. ed., São Paulo: Hucitec; Rio de Janeiro: Abrasco, 2000. 
MIOT, Hélio Amante. Avaliação da normalidade dos dados em estudos clínicos e experimentais. Vasc Bras. 2017 Apr.-Jun.; v.I6, n. 2, pag. 88-9I. Disponível: 〈https://www.scielo.br/pdf/jvb/vi6n2/1677-5449-jvb-16-2-88.pdf〉.

NOBRE, Ilana Elen Andrade Mariano et al. Sistema de classificação de pacientes de Fugulin: perfil assistencial da clínica médica. Revista de Enfermagem UFPE on line, [S.1.], v. II, n. 4, p. 1736-1742, mar. 2017. ISSN 1981-8963. Disponível em: 〈https://periodicos.ufpe.br/revistas/revistaenfermagem/article/view/15245〉. Acesso em: 20 nov. 2021.

OLIVEIRA, Patrícia Veras Neves de; et al. Formação do enfermeiro para os cuidados de pacientes críticos na Unidade de Terapia Intensiva. Nursing (São Paulo), \{S. I.\}, v. 22, n. 250, p. 2751-2755, 2019. $\quad$ Disponível em: $\langle$ http://revistas.mpmcomunicacao.com.br/index.php/revistanursing/article/view/289>. Acesso em: 2 nov. 2021.

PADILHA, Katia Grillo et al. Therapeutic intervention scoring system-28 (TISS-28): diretrizes para aplicação. Rev. Esc. Enferm. USP, São Paulo, v. 39, n. 2, p. 229-233, June 2005. Disponível em: $\quad\langle$ http://www.scielo.br/scielo.php?script=sci_arttext\&pid=Soo8o623420050002000I4\&lng=en \&nrm=iso $>$. Acesso em: 13 fev. 2020 .

QUEIJO, Alda Ferreira. Tradução para o português e validação de um instrumento de medida de carga de trabalho de enfermagem em Unidade de Terapia Intensiva: Nursing Activities Score (NAS). [dissertação]. São Paulo: Escola de Enfermagem, Universidade de São Paulo. 2002.

QUEIJO, Alda Ferreira; PADILHA, Kátia Grillo. NURSING ACTIVITIES SCORE (NAS): adaptação transcultural e validação para a língua portuguesa. Rev. Esc. Enferm. USP. v. ${ }_{43}$ (Esp), pag. I0I8-I025, 2009. Disponível em: $\langle$ https://www.scielo.br/pdf/reeusp/v43nspe/a04v43ns.pdf $>$. Acesso em 20. abr. 2019. RODRIGUES, Maria Auxiliadora; DE PAULA, Rodolpho César Cardoso; SANTANA, Rosimere Ferreira. Divergências entre legislações do dimensionamento de enfermagem em unidades de terapia intensiva. Enfermagem em Foco, [S.1.], v. 8, n. I, p. 12-16, abr. 2017. ISSN $2357-707 \mathrm{X}$. $\langle$ http://revista.cofen.gov.br/index.php/enfermagem/article/view/758〉. Acesso em: 02 nov. 2021. 
SANTOS, Fernanda dos et al. Sistema de classificação de pacientes: proposta de complementação do instrumento de Fugulin. Rev. Latino-Am. Enfermagem, Ribeirão $\begin{array}{lllll}\text { Preto, v. } & \text { I5, n. } & \text { 5, p. } & \text { 980-985, out. } & \text { Disponível }\end{array}$ em:<http://www.scielo.br/scielo.php?script=sci_arttext\&pid=Soro4II692007000500oI5\&lng=en\& $\mathrm{nrm}=$ iso $>$. Acesso em i3 fev. 2020.

SILVA, A. P. F.; CARNEIRO, L. V.; RAMALHO, J. P. G. Burnout syndrome among critical care nursing professionals / incidência da Síndrome de burnout em profissionais de enfermagem atuantes em unidade de terapia intensiva. Revista de Pesquisa Cuidado é Fundamental Online, [S. 1.], v. 12, p. 915-920, 2021. DOI: 10.9789/2175-5361.rpcfo.vi2.7986. Disponível em: http://seer.unirio.br/cuidadofundamental/article/view/7986. Acesso em: 2 nov. 202I.

SOUZA, P. T. L. de; FERREIRA, J. de A.; OLIVEIRA, E. C. da S.; DE LIMA, N. B. A.; CABRAL, J. da R.; DE OLIVEIRA, R. C. Necessidades humanas básicas em terapia intensiva. Revista de Pesquisa Cuidado é Fundamental Online, [S. 1.], v. II, n. 4, p. IoII-ıor6, 2019. DOI: I0.9789/2175-536r. 2019. viri4.Ioli-ıor6. Disponível em: http://www.seer.unirio.br/cuidadofundamental/article/view/6850. Acesso em: 2 nov. 202I. VANDRESEN, Lara et al. Classificação de pacientes e dimensionamento de profissionais de enfermagem: contribuições de uma tecnologia de gestão. Rev. Gaúcha Enferm., Porto Alegre , v. 39, e2017-0107, 2018 . Disponível em 〈http://www.revenf.bvs.br/scielo.php?script=sci_arttext\&pid=SI983I447201800o100426\&lng=pt\&nrm=iso $>$. Acesso em 02 nov. 202I. Epub 02-Ago-2018. VIGNA, Cinthia et al. Utilização de Sistema de Classificação de Pacientes e métodos de dimensionamento de pessoal de enfermagem. ArqCiênc Saúde 2007 jan-mar;14(I):8-I2. ISSN 15055-290. Disponível em: <https://repositorio-racs.famerp.br/racs_ol/vol-I4I/id215.pdf $>$ Acesso em: I2 out. 202I. 